\begin{tabular}{|c|c|c|c|}
\hline 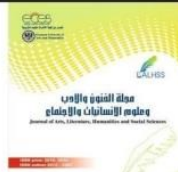 & 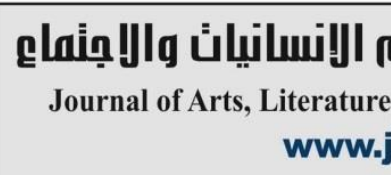 & $\begin{array}{l}\text { es and Social Sciences } \\
\text { m }\end{array}$ & \\
\hline$=\quad=$ & Volume (70) August 2021 & العدد (70) أغسطس 2021 & \\
\hline
\end{tabular}

\title{
The Effect of Self-voice Recording Technique on Oral Performance of EFL learners in Electronic Learning
}

\author{
Asmaa Hussain Jaber \\ Department of English - Imam Al-Kadhum University College - Baghdad - Iraq \\ E-mail: asmaa.2019@alkadum-col.edu.iq
}

\begin{abstract}
The recent COVID-19 pandemic has negatively affected each sector in society. Likewise, even the education system has been affected in many countries as governments across the globe have temporarily closed all educational institutes for curbing the spread of this virus. With the cancellation of all face-to-face classes, the teachers have resorted to online classes and online learning, thereby allowing the students to continue their education. However, this transition from the traditional face-to-face classes to online classes has given rise to many challenges for the teachers, students, school administrators and even the leaders.

The teachers have been compelled to design new tools and techniques that can help the students learn and understand their lessons. These tools also help the teachers cooperate with the students like their interaction during the face-to-face classes. Hence, in this study, the researchers have used a self-voice recording technique for determining its effect on the speaking skills of the students along with their perspectives. For this purpose, they interviewed 100 University students studying in an English conversation class. All data were collected using a questionnaire, or through class observation, where the learners carried out self-voice tasks. Some significant results noted in this study were - Firstly, the students showed a lot of interest in electronic learning and using self-voice techniques, even though many of them had never experienced it before. Secondly, the students displayed a positive perspective and were interested in using the self-voice recording techniques for elearning. Thirdly, the students noted that the self-voice recording technique offered them numerous chances to put forth their point, which allowed them to enjoy their interactions. However, they asked for more corrective feedback. Lastly, it was observed that the self-voice recording technique was very effective in e-learning as it improved the speaking skills of the students. After reviewing the findings of the study, the researchers have offered some suggestions in this study.
\end{abstract}

Keywords: Self-Voice recording, electronic learning, oral performance. 


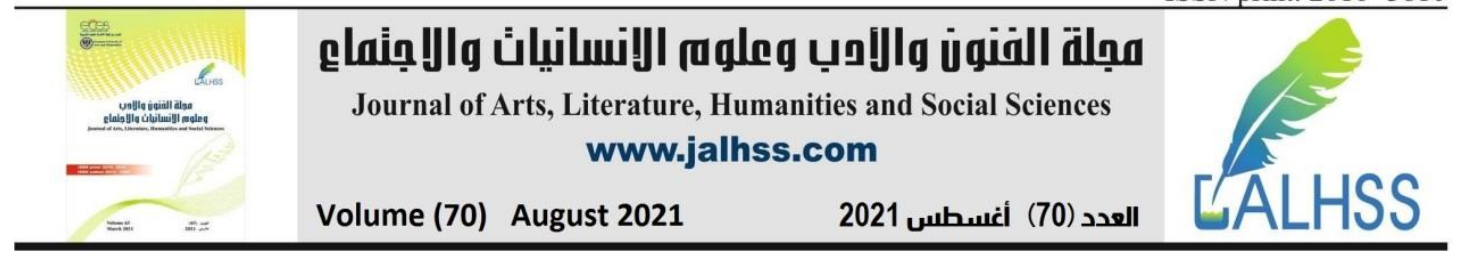

\section{Introduction:}

\subsection{Research Problem and its Significance}

Many teachers have found that a majority of the students need help while speaking and pronouncing words during a conversation class. Hence, due to a lack of time, they find it difficult to listen to each student in a traditional classroom. Also, they state that during the speaking activities in the classroom, the students who work in pairs or groups, need to focus more on their fluency instead of the accuracy of their spoken words. Thus, the teachers find it challenging to provide proper guidance and offer feedback to the students who desire help for improving their speaking skills. The COVID-19 pandemic has further disrupted the education system as many schools, colleges and universities across the globe, had to close down their classes. To allow the students to continue their education, many face-to-face classes had to be shifted online. This led to the development of a new teaching format, where lessons, lectures and learning activities could be conducted remotely. However, online classes are not a new concept in the developed societies. It forms a major component of the student curriculum. These students are familiar with the various aspects related to online learning as they regularly use different learning management systems or tools like Blackboard, Moodle, etc. Hence, the instructors need to design novel techniques to co-operate with the students and help them in a manner similar to that used in the actual classroom.

In this study, the researchers have presented an alternative technique to teach English as a Foreign Language (EFL) in a teacher-centred class, by using new technology (i.e., self-voice recorder). This new technology offers the teacher a lot of freedom during teaching and also helps the students learn more effectively. The teachers can use this technique while teaching different speaking skills which are a basic component of the curriculum that was designed for the university students learning EFL. The researchers have aimed to determine the impact of using these devices (i.e., self-voice recorder) while improving the oral performance of these students in comparison to the traditional techniques. This study can be significant as there are no earlier reports where the researchers have applied this technology in the Iraqi Educational sector.

\subsection{Aim of This Study:}

In this study, the researchers have aimed to determine the level to which the self-voice recorder technique can promote the English-speaking skills of the Iraqi student majors. They also aim to determine whether the use of this technique could improve the English-speaking skills of the students. Finally, the researchers have also sought the opinions of the participants with regards to activities that could improve their speaking abilities. For fulfilling these objectives, the researchers circulated a questionnaire and collected answers to the above-mentioned research problems.

\subsection{Research Questions:}

The following research questions were raised in this study: 


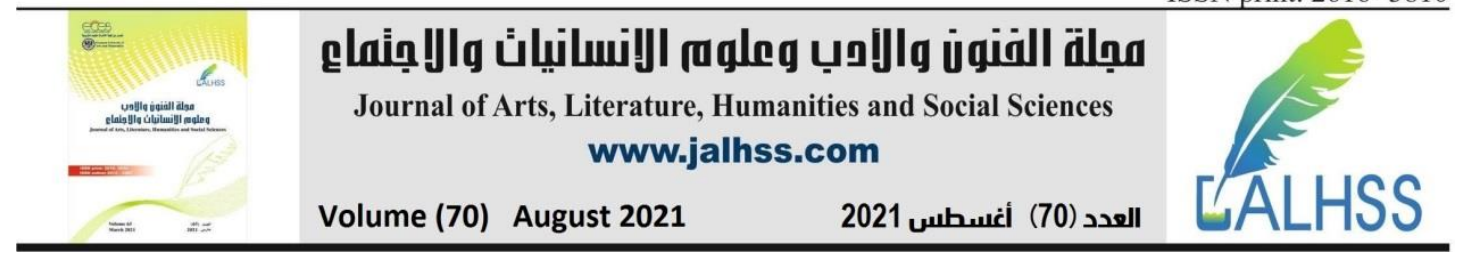

1) What is the experience and interest level of the students and teachers while using the self-voice recording technique during the teaching and learning of EFL during elearning classes?

2) What are the perspectives of the students with regards to the use of the self-voice recording technique during the teaching and learning of EFL during e-learning classes?

3) What are the significant effects of using the self-voice recording technique on the learning skills of the students during e-learning classes?

\subsection{Limits of this study:}

This study was limited to:

1. Semester 1 of the academic year 2020-2021.

2. Stage 3 students studying in the English Department at the Imam Al-Kadum University College, Baghdad, Iraq, who attended 2 virtual classes (i.e., morning studies) on the Google classroom platform. A total of 100 students were selected for this study.

3. The subject matter that was allocated and included in the curriculum of the junior students was derived from the book called 'Real Listening and Speaking' by Miles Craven. This topic focused primarily on the listening and communicative speaking skills of the students.

\subsection{Value of this study:}

This study could be very helpful as it encouraged the English language Teachers at different Iraqi schools to use and adapt the self-voice recording technique while teaching oral and listening skills.

\subsection{Significance of this study:}

This study is important for the Iraqi English language learners and teachers as it can encourage them to adopt novel techniques that could help them learn the English language effectively.

\subsection{Literature review:}

Numerous voice recording tools are being used in different ways in the language instruction process for providing the learners with ample opportunities for generating oral output. These tools could help the language students to practice and improve their speaking skills outside a classroom and also receive feedback for their performance (Pop et al., 2011).

Several theories and studies have suggested that the output was essential for learning a second language. According to Swain and Lapkin (1995), the output was significant as it promoted observation and even fluency. The output from the learners can be increased by recording their performance so that they could listen, analyse and edit their recorded material. The first recording tool that was used in a learning class included the cassette tapes, where the students carried cassette recorders for recording and listening to their oral performance. However, due to the digitalisation of the voice 


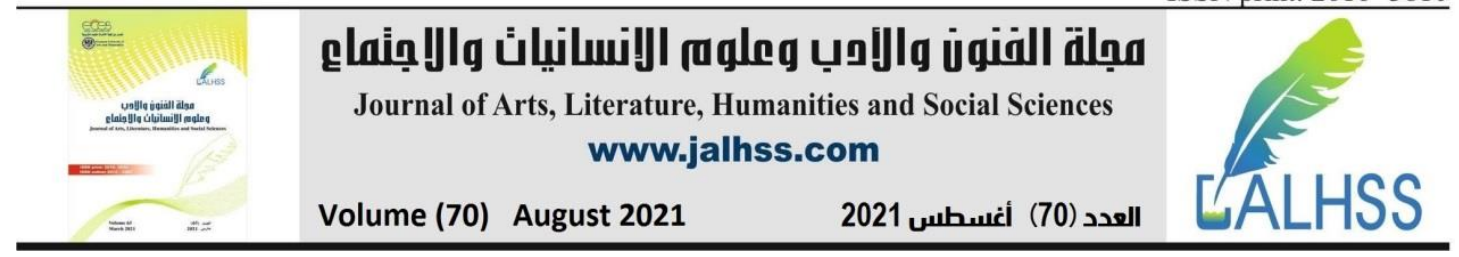

recording techniques/ tools and an increasing rate of internet access, worldwide, there was increased feasibility of incorporating various learning tools and further improving the probable use of voice recording tools in the language learning sessions (Cooke 2013).

All these tools and techniques enable the students to record their voice during the learning classes and then transmit these audio files. Different podcasts, voice e-mails and audio blogs are seen to be a popular technique of incorporating speaking activities outside the classrooms. The emerging technologies have improved the effectiveness of the distant language and self-learning processes with regards to audio/oral skills. The speech recognition and synthesis technologies have become very popular in various learning settings and must be regarded as effective voice recording tools. In this study, the researchers have primarily focused on the potential of the voice recording techniques that can supplement classroom instructions. Though videotaping is generally regarded as an important learning tool, only voice recording tools are included in language instruction for in-class activities or homework (Ibid).

\subsection{Voice Recording Technique:}

Technology is often used for teaching a foreign language in the classroom; however, it has shifted from audiotapes to CDs. The students no longer need to carry poorquality microphones or unwieldy cassette players. Currently, modern technological tools like digital audio recordings allow an unprecedented comfort while collecting student-generated voice recordings in the classrooms. Digital audio recording is regarded as an effective tool for teaching foreign languages in the classrooms wherein the main goal was to practice speaking the foreign language, listen to the sound of the words and thus increase their speaking proficiency.

This type of self-monitoring is a vital step in learning any language for all levels of students (Gomez and Lowe 1995). Many free and easy-to-use smartphone applications like voice recording tools are used for documenting the practice sessions where the students speak their target language. When the students use these applications while speaking the foreign language, their practice lessons are recorded and the students are able to listen to these sessions before sending the audio lessons to their instructors. Thus, the students can reflect on their grammar, fluency, accent, intonation, etc.

The audio recordings are an effective tool as the students can generate a complete collection of their voice recordings which indicates their improvement over a time period. All these audio recordings can be shared with their instructors and peers. A voice recording app is an easy tool that is used by language learners for making basic audio recordings. The learners click a single button, record their audio lessons and select from various ways to save the recordings, such as a downloadable MP3 file. Thereafter, they can share their audio files to their class telegram and WhatsApp groups with their peers and language instructors for collecting their feedback (Huang 2008). 


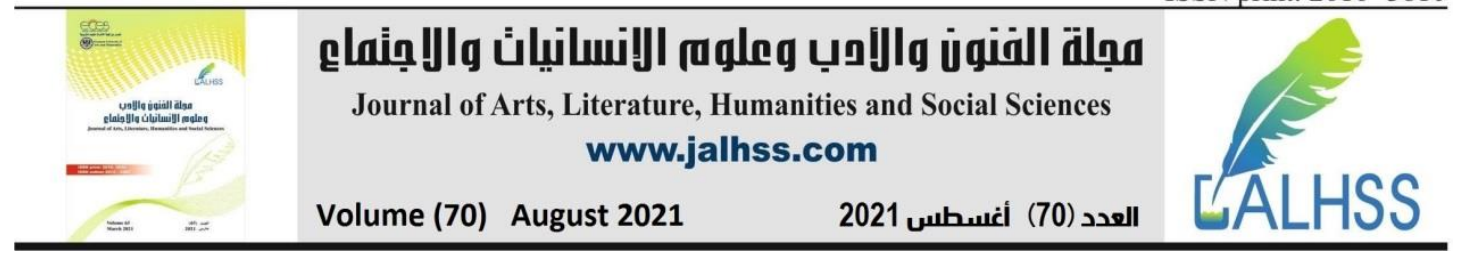

\subsection{Voice recording activities while improving the students' oral fluency:}

Pop et al. (2011) introduced many voice-recording tools that can be used in different ways for language instruction. These can be used for providing ample opportunities to the learners so that they can generate an oral output. These tools allow the language students to effectively practice and improve their speaking skills outside their classrooms, and also receive feedback for their performance (2011). After using the easy-to-use voice recording tools and applications available on smartphones, the learners can save their practice oral lessons for self-assessment. The recent developments noted in the tablet and mobile applications offer various ways to the students for saving their voice lessons and recording themselves while speaking. Thereafter, their instructors listen and provide constructive feedback to their oral performance and assist the students to review their performance.

\subsection{Electrical Learning:}

E-learning is defined as a science of learning without the use of any paper-printed instructional materials. It further refers to the use of telecommunication technology for delivering important information for training and education purposes. Due to the progress of the information and communication technological activities, e-learning has emerged as a paradigm of modern educational systems. E-learning processes increase the liberating interactions between the instructors and learners. It can be used despite the limitations of space and time as it involves many synchronous and asynchronous learning network models (Sun et al., 2008).

E-learning processes refer to the intentional use of network information and communication technology during teaching and learning processes. Many terms can be used for describing this type of teaching and learning activities, such as distributed learning, virtual learning, online learning, network and web-based learning. Elearning is more than just online learning since the alphabet " $\mathrm{e}$ " in E-learning indicates the term, "electronic". Thus, e-learning incorporates all the educational activities conducted by groups of people working in an online or offline environment (Naidu 2006).

\section{Methodology:}

\section{3 .1 Experimental Design:}

In this study, the researchers aimed to examine the effectiveness of using the selfvoice recording technique on the oral performance of the EFL learners in e-learning processes. For this purpose, they developed a quantitative experimental design that includes a control group. The test and control groups were recruited using a coin flip. These experiments were conducted for 3 months, between January and April 2021. The subjects used in the study were $3^{\text {rd }}$ stage students studying in the English Department at the Imam Al-Kadum University College. These students attended 2 virtual classes (morning studies) on the Google classroom platform. A total of 100 students were recruited in this study, where the control group consisted of 50 students while the test group included 50 students. These students were used as a population sample after the researchers used the purposive sampling technique. They used 


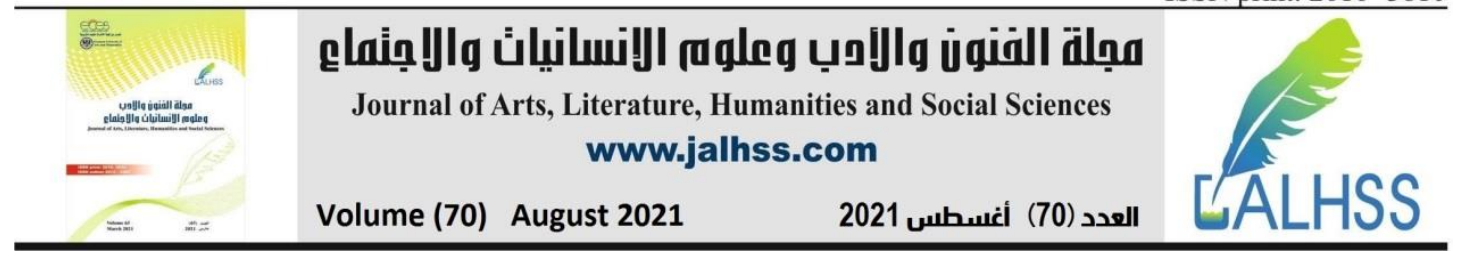

Google meetings for attending their lectures. Their learning process underwent 3 stages, i.e., preparation, implementation, and closing. During the preparation stage, the lecturer formulated the objectives at their meetings, determined the subject matter and prepared the tools in the Google meet media. The preparation phase also includes all arrangements for tools like microphones and laptops, so that the lessons can be delivered and heard properly by the students. In the implementation stage, the lecturers open and present the material through the Google Meet App. Finally, the concluding phase summarises the subject matter which has been taught. Here, after presenting the material, the researchers asked the students to carry out a few basic tasks which would help them recall the material that was presented using self-voice recording tasks and recording functions present on their smartphones. Finally, they are asked to upload all matter on the telegram groups within 2 days.

The topics are discussed in the class depending on the content included in the course books, which includes Listening and speaking (Craven 2009). The topics for the weekly voice task have been presented in Table 1 and are based on classroom readings and activities. The students are given 2 days for submitting their online peer feedback regarding the class. The students are also given many opportunities to receive the teacher's feedback. They are given 10 different topics and when the study progresses, they are presented with more choices for selecting their topics for selfvoice recordings. Out of the 10 topics, the first and last self-voice recording tasks are further analysed for determining the effectiveness of the self-voice recording technique during the e-learning process.

Table 1: Topics for the Weekly Voice tasks

\begin{tabular}{|l|l|}
\hline Unit & Topics for the tasks \\
\hline 1. 1. I am looking for a camera & $\begin{array}{l}\text { Make conversation telling your friend about buying an } \\
\text { electronic item and how can you negotiate and make a } \\
\text { good deal }\end{array}$ \\
\hline 2. 2. How is it going? & $\begin{array}{l}\text { Make conversation in which you are at a party. Use follow- } \\
\text { up questions as much as possible }\end{array}$ \\
\hline 3. 3. I need to see a doctor & What is the European Health Insurance Card? \\
\hline 4. What is the problem? & $\begin{array}{l}\text { Imagine your computer isn't working and your friends } \\
\text { suggest a number of probable causes }\end{array}$ \\
\hline 5. What a lot of red tape! & What is a green card? \\
\hline 6. What a great view! & $\begin{array}{l}\text { Imagine you are showing a friend around your home town. } \\
\text { Make conversation about the places of interest }\end{array}$ \\
\hline 7. I would appreciate it & What do the colours in your home country's flag represent? \\
\hline 8. This is your office & Do you think our lives have been improved by the \\
\hline
\end{tabular}




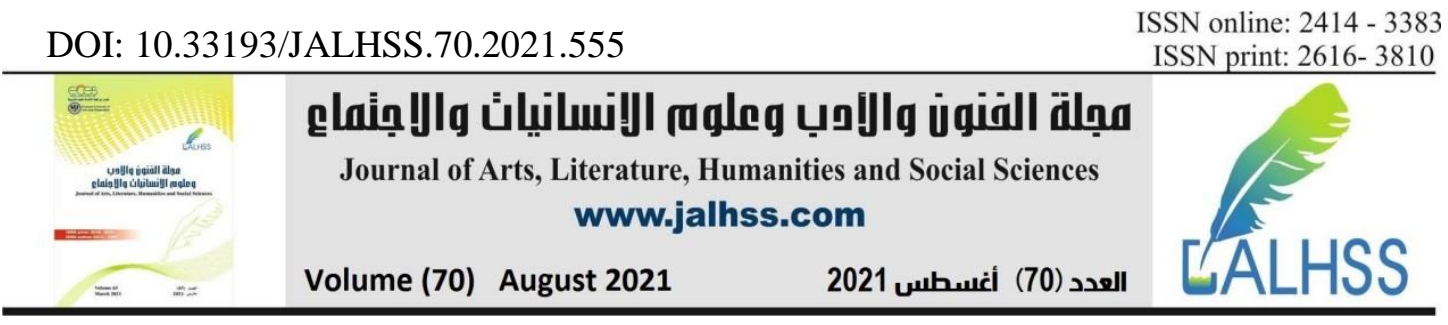

\begin{tabular}{|l|l|}
\hline 9. I will sort it out & Internet? \\
\hline 10. Can I call you back? & $\begin{array}{l}\text { Do you think that English will completely dominate all the } \\
\text { other languages in future? If yes, how will it affect the } \\
\text { world? }\end{array}$ \\
\hline $\begin{array}{l}\text { Do you think it's necessary to have plastic surgery in order } \\
\text { to be beautiful? }\end{array}$ \\
\hline
\end{tabular}

\section{2 Population and Sample Administration:}

\subsubsection{Population}

Richard et al. (1992) defined a population as a set of individuals, items, etc., that are similar with regards to their sampling properties. In this study, a population refers to $3^{\text {rd }}$-year students studying in the English Department at Imam AL-Khadum College in Baghdad during Semester 1 (January to April) in the academic year of 2020-2021.

\subsubsection{Sample}

The participants in this study included the students from the electronic junior classes who were studying English through the Google classroom platform and attended the Imam Alkhadum College in Baghdad, Iraq. The total sample size was 100 students who were further divided into 2 groups. Section A comprised of the experimental group containing 50 students (i.e., students who used the self-voice recording technique), while Section B contained the control group of 50 students (who were taught their speaking skills in the traditional manner). All these students have Arabic as their mother tongue. The junior major English students were selected as the participants in this study due to the following reasons:

1- The Junior students could easily handle the internet-based instructions.

2- The topic that was taught to these junior students in their prescribed textbooks was known as 'Real Listening and Speaking' by Miles Craven. This topic focused primarily on the communicative speaking and listening skills of the students.

3- As these students could teach the English language in future, they could derive maximal benefits from this research as they could use different electronic devices in their future teaching lessons.

\subsection{Data Collection Instrument:}

In this study, the researchers collected both qualitative and quantitative data. The qualitative data that was collected was based on the online classroom observations and interviews of the students. On the other hand, the quantitative data were collected for determining the students' perspectives through questionnaires. This helped the researchers determine the students' viewpoints regarding the self-voice recording process and e-learning in L2 speaking. The researchers distributed the questionnaire amongst the participants. The respondents were given a link for a Google form. For investigating the effect of using the self-voice recording technique during e-learning class on the speaking skills of the students, the researchers analysed the first and last voice. The student-generated recordings were analysed by the researchers. Thereafter, 


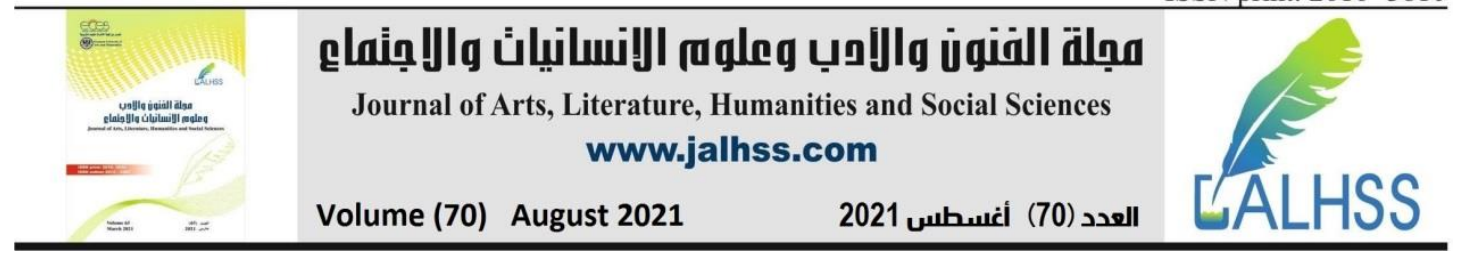

they scored the voice recordings using rubric values based on the 4 features of speaking, i.e., suprasegmental, segmental, fluency, and accuracy. Table 2 presents these results. The researchers also considered the oral proficiency of the scoring categories presented by Brown (2004) along with the Test of Spoken English scoring guidelines (Educational Testing Service 1995) while developing the rubric scores for analysing the speaking skills of the students.

Table 2: Rubric Scores for Speaking Skills:

\begin{tabular}{|c|c|c|c|}
\hline Supra-segmental 25 points & Fluency 25 points & Segmental 25 points & Accuracy 25 points \\
\hline $\begin{array}{l}\text { Intonation } \\
\text { Word } \\
\text { connection } \\
\text { Reduction }\end{array}$ & $\begin{array}{l}\text { Speech Rate } \\
\text { Repair } \\
\text { Length of run and } \\
\text { filled pauses }\end{array}$ & $\begin{array}{l}\text { Vowels } \\
\text { Consonants }\end{array}$ & $\begin{array}{l}\text { Vocabulary } \\
\text { Grammar } \\
\text { Organisation }\end{array}$ \\
\hline
\end{tabular}

\section{Results:}

\section{a. Students' Interest and Experience in Using Electronic Learning and Self-voice Recording Techniques:}

Here, the researchers aimed to understand whether the students were interested and experienced in using the e-learning platforms. Firstly, the researchers determined if the respondents showed a positive response and were interested in using the elearning platforms for their English-speaking classes. 87.1\% of the respondents were interested $(25.8 \%$ were very interested, while $61.3 \%$ were fairly interested). On the other hand, $12.9 \%$ of the respondents were indifferent. None of the students stated that they were uninterested. The results of the questionnaire indicated that the students' interest level in using the e-learning platforms was high. They considered elearning processes as an innovative and effective technique to study and learn English. Hence, they displayed a very positive response to these techniques.

Secondly, the researchers determined if the students were experienced in using the elearning platforms. Here, e-learning techniques were used to offer an online elearning environment to the students, which ensured an effective interaction between the learners, learners and teachers and between the learners and multimedia.

The results indicated that the respondents responded negatively when they were asked about their prior experience while using e-learning classes. Out of all the respondents, $46.8 \%$ of the students stated that they had attended e-learning classes in the past while $53.2 \%$ of the students had not attended any e-learning classes before this study. On the other hand, the students displayed a positive interest when asked to use selfrecording techniques while attending English speaking classes. $80.7 \%$ of the respondents expressed their interest (where $8.1 \%$ of the respondents were very interested while $72.6 \%$ were fairly interested). $19.4 \%$ of the participants were indifferent. However, none of the participants stated that they were not interested. 


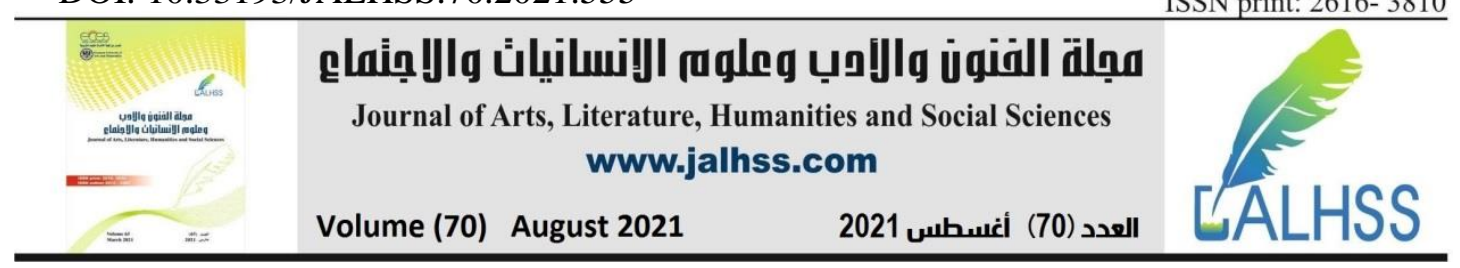

Finally, the respondents responded negatively when they were asked about their experience in using the voice recording for academic purposes. Out of the total respondents, $88.6 \%$ of the respondents had never used any voice journal in their classes, while $4.0 \%$ of the respondents had used voice journals in their classes before. Thus, the researchers concluded that a majority of the respondents had no prior experience in using voice journals for their English classes.

Table 3: Students' interest and experience in using e-learning and voice recording techniques

\begin{tabular}{|l|l|l|l|}
\hline Interest and Experience & Value & df & Sig \\
\hline Interest in e-learning & 3.397 & 2 & 0.183 \\
\hline $\begin{array}{l}\text { Prior experience of using e-learning techniques in } \\
\text { classes }\end{array}$ & 2.2381 & 1 & $0.327 \mathrm{I}$ \\
\hline Interest in using self-voice recording techniques & 1.652 & 2 & 0.438 \\
\hline Prior experience in using self-voice recording & 1.905 & 1 & 0.292 \\
\hline
\end{tabular}

4.2 Students' Perspectives regarding the use of self-voice Recording Techniques:

Table 6 presents the students' perspectives regarding the use of the self-voice recording technique. According to the consensus, the students expressed a positive response. Firstly, the students considered this technique very interesting and hence expressed a positive interest. The results indicated that the average value for interest was maximal out of the different levels such as usefulness, interest, ease and satisfaction. Thus, the researchers concluded that the respondents found the self-voice recording technique to be very interesting (3.23), followed by satisfying (3.13); useful (3.03) and easy to use (2.56), respectively. It must be noted that the male students' response towards the ease of using the technique was 2.44 , which was negative. However, no significant difference was noted based on gender, as a total value of 2.56 indicated a positive response with regards to the ease in using the technique.

Table 4: Students' Perspectives regarding the use of Self-voice Recording Techniques

\begin{tabular}{|l|l|l|l|l|l|}
\hline Mean & Female & Male & Total & df & sig \\
\hline Interest & 3.23 & 3.28 & 952 & 1 & 333 \\
\hline Usefulness & 3.03 & 3.08 & 399 & 1 & 530 \\
\hline Easiness & 2.56 & 2.44 & 2.475 & 1 & 121 \\
\hline Satisfaction & 3.08 & 3.17 & 350 & 1 & 556 \\
\hline
\end{tabular}

\subsection{Student's Performance in Using Self-voice Recording Technique}

The researchers analysed the first and last self-voice recording task entries from BBS for their segmental features, suprasegmental features, fluency, and accuracy based on the rubric scores (Table 2). The researchers aimed to determine the effectiveness of using the self-recording voice technique for e-learning. An increase was noted across the board from the $1^{\text {st }}$ to the last self-voice task entry. The segmental category showed 


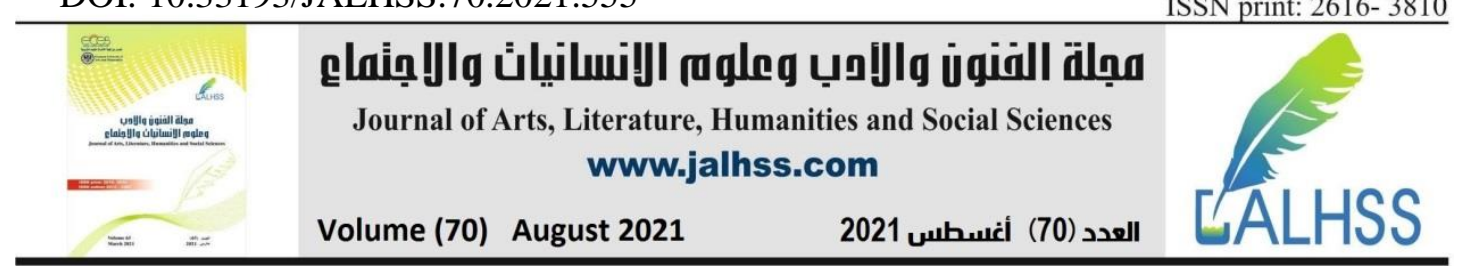

a 3.28-point increase from 12.24 to 15.52 points, whereas a 4.39 -point increase was noted in the suprasegmental category, from 10.37 to 14.76 points. In the case of accuracy, a 2.79-point increase was noted from 14.29 to 17.26 points while a 3.6point increase was noted in the fluency category from 12.11 to 15.71 points. A 14.03 point increase was seen from 49.02 to 63.05 points for the 4 categories. The highest increase was seen in the segmental features, followed by fluency, suprasegmental features, and accuracy. As accuracy displayed the maximal score for the self-voice Tasks 1 and 10, the students tend to pay a lot more attention to the categories that were lacking like segmental features and fluency.

Table 5: T-Test for the self-voice recording tasks:

\begin{tabular}{|l|l|l|l|l|l|l|l|}
\hline & Voice task & $\mathrm{N}$ & Mean & SD & $\mathrm{T}$ & $\mathrm{DF}$ & $\mathrm{P}$ \\
\hline Segmental & 1 & 35 & 12.24 & $3.273-$ & -6.335 & 34 & .000 \\
& 10 & & 15.52 & 3.212 & & 34 & .000 \\
\hline Supra- & 1 & 35 & 10.37 & 3.179 & & 34 & .000 \\
segmental & 10 & & 14.76 & 2.895 & 8.970 & 34 & .000 \\
\hline Accuracy & 1 & 35 & 14.29 & 2.769 & -5.928 & 34 & .000 \\
& 10 & & 17.26 & 3.603 & & 34 & .000 \\
\hline Fluency & 1 & 35 & 12.11 & 3.006 & 7.070 & 34 & .000 \\
& 10 & & 15.71 & 3.169 & & 34 & .000 \\
\hline Total & 1 & 35 & 49.02 & 11.230 & -8.226 & 34 & .000 \\
& 10 & & 63.05 & 11.256 & & & .000 \\
\hline
\end{tabular}

A significant difference was noted between the self-voice recording Tasks 1 and 10 for all the 4 categories presented in Table 8 . This highlighted the improvement in the students' speaking skills. The use of a self-voice recording task in e-learning for the EFL speaking classes was effective in the 4 categories of segmental features, suprasegmental features, accuracy, and fluency.

\section{Conclusions:}

In this study, the researchers have investigated the students' perspectives regarding the use of the self-voice recording techniques for e-learning in the EFL university classrooms. They also determined its effect on the oral performance of the EFL learners. The major findings have been presented below:

Firstly, the students were very interested in using the e-learning techniques. However, more than $50 \%$ of the respondents had never used this process before. Similarly, the students expressed an interest in using the self-voice recording technique though a majority of the respondents had never used this technique before.

Secondly, the respondents' perspective on the use of the self-voice recording technique was positive with regards to the interest, satisfaction, usefulness and ease of use. The respondents showed a positive response to the use of these techniques though they had never experienced and used these techniques in the past. Based on these results and after considering the earlier results regarding the higher satisfaction levels 


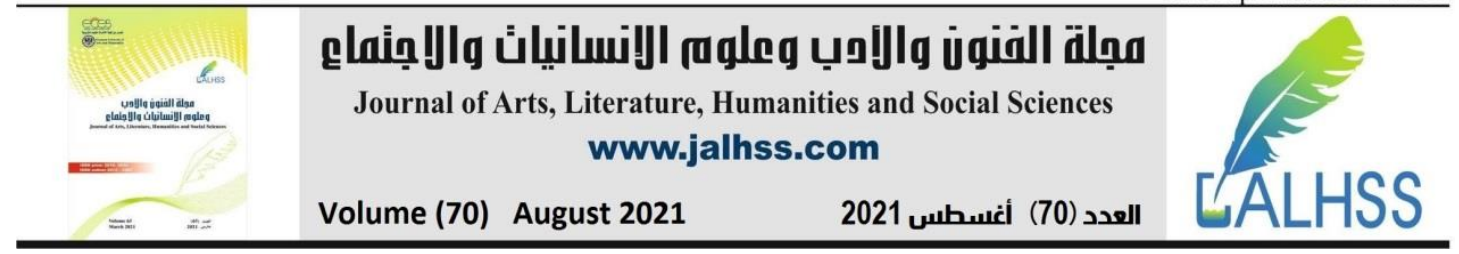

while using the multimedia tools, the researchers concluded that the respondents' perspectives on the use of the self-voice recording techniques were positive.

Thirdly, the respondents reflected on the use of these techniques for 15 weeks and concluded that they appreciated these technologies and liked an online environment as it provided them many opportunities for learning and practising their speaking skills. They also noted that e-learning classes provided them with numerous opportunities to interact with each other and their teachers. However, some issues were also highlighted. Some of the students stated that peer feedback included some comprehensive comments regarding the content of voice journals, however, they wanted an explicit and straightforward error correction step. It was seen that even though the students were aware of some mistakes in the voice recordings, they were not confident enough to point them out or offer corrective feedback. This was attributed to the fact that the respondents included in the study were beginners. Thus, the researchers recommended that for the beginner students, the teachers must provide their feedback in addition to the corrective feedback.

Fourthly, the researchers analysed the $1^{\text {st }}$ and last self-voice recording entries provided by all the students for determining the effectiveness of using the voice journals in e-learning classes and analysing the EFL students' speaking skills. These recordings were very effective in improving different categories like segmental features, suprasegmental features, accuracy, and fluency. A maximal improvement was noted in the segmental features, while accuracy displayed minimal improvement. However, it must be noted that the accuracy factor showed the maximal score in the 4 areas for the $1^{\text {st }}$ and last voice entries. The results presented in the study led to the conclusion that the use of self-voice recording techniques in e-learning classes positively influenced the EFL students' oral skills. The students also presented a positive perspective towards the use of these techniques. 


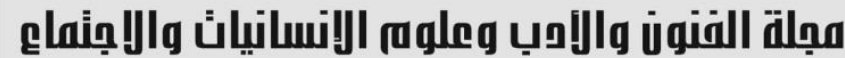 \\ Journal of Arts, Literature, Humanities and Social Sciences www.jalhss.com

\section{References}

1. Cooke, S. D. (2013). Examining Transcription, Autonomy and Reflective Practice in Language Development. RELC Journal, 44(1), 75-85.

2. Gomez, A.M., Arai, M.J., and Lowe, H. (1995). When Does a Student Participate in Class? Ethnicity and Classroom Participation. Paper presented at the Annual Meeting of the Speech Communication Association (81st, San Antonio, TX).

3. Huang, S. C. (2008). Raising Learner-Initiated Attention to the Formal Aspects of Their Oral [6] Production through Transcription and Stimulated Reflection. IRAL-International Review of [7] Applied Linguistics in Language Teaching, 46(4), 375-392.

4. Naidu, S (2006). E-Learning: A Guidebook of Principles, Procedures and Practices, 2nd Revised Edition, CEMCA.

5. Pei-Chen Sun, Ray J. Tsai, Glenn Finger, Yueh-Yang Chen, Dowming Yeh,

6. Pop, A., Tomuletiu, E. A., and David, D. (2011). EFL speaking communication with asynchronous voice tools for adult students. ProcediaSocial and Behavioral Sciences, 15, 1199-1203.

7. Swain, M., and Lapkin, S. (1995). Problems in output and the cognitive processes they generate: A step towards second language learning. Applied Linguistics, 16(3), 371-391.

8. What drives a successful e-Learning? An empirical investigation of the critical factors influencing learner satisfaction, Computers and Education, Volume 50, Issue 4,2008. 